\title{
A Case of Early Prosthetic Valve Endocarditis Caused by Staphylococcus warneri in a Patient Presenting With Congestive Heart Failure
}

\author{
Maita S. Kuvhenguhwa ${ }^{\mathrm{a}, \mathrm{c}}$, Kevin O. Belgrave ${ }^{\mathrm{b}}$, Sonia U. Shah ${ }^{\mathrm{b}}$, \\ Arnold S. Bayer ${ }^{\mathrm{a}}$, Loren G. Miller ${ }^{\mathrm{a}}$
}

\begin{abstract}
Staphylococcus warneri, a coagulase negative staphylococcus, has been isolated in prosthetic device-related infections and has been reported as a rare cause of endocarditis. We report a case of prosthetic aortic valve $S$. warneri endocarditis, in which the patient lacked typical infectious signs and symptoms, instead presenting with congestive heart failure due to perforation of the valve. Providers should consider endocarditis with a low virulence pathogen such as $S$. warneri when a patient with a prosthetic valve presents with heart failure, even in the absence of fever, leukocytosis and other infectious symptoms.
\end{abstract}

Keywords: Staphylococcus warneri; Prosthetic valve endocarditis

\section{Introduction}

Staphylococcus warneri is a member of the coagulase negative staphylococci (CoNS), occasionally isolated in cases of nosocomial bacteremia and typically associated with the presence of prosthetic devices such as dialysis catheters. It has been recognized as an uncommon cause of infective endocarditis with eight prior cases described in the English literature, six of which involved native valves and two of which involved prosthetic valves [1-7]. Herein, we present a case of prosthetic aortic valve endocarditis, in which the patient presented with symptoms of congestive heart failure (CHF) and the possibility of endocarditis was raised by new valvular dysfunction on echocardiography.

Manuscript submitted August 13, 2017, accepted August 31, 2017

aDivision of Infectious Diseases, Harbor-UCLA Medical Center, Torrance, CA, USA

bDepartment of Cardiology, Habor-UCLA Medical Center, Torrance, CA, USA

${ }^{\mathrm{c} C o r r e s p o n d i n g ~ A u t h o r: ~ M a i t a ~ S . ~ K u v h e n g u h w a, ~ H a r b o r-U C L A ~ M e d i c a l ~}$ Center, 1000 W. Carson St, Box 466, Torrance, CA 90509, USA.

Email: maita.kuvhenguhwa@gmail.com

doi: https://doi.org/10.14740/cr588w

\section{Case Report}

A 67-year-old man presented to the emergency department (ED) complaining of stabbing chest pain, subjective fevers, chills, watery diarrhea, nausea and vomiting for 1 week. His past medical history was notable for three vessel coronary artery bypass grafts and a $23 \mathrm{~mm}$ bioprosthetic aortic valve replacement surgery 7 months prior, and an ischemic stroke 2 months prior that left him with residual left-sided hemiparesis. In the ED, he was found to have atrial fibrillation with rapid ventricular response and a heart rate in the 130s (Fig. 1). His exam was notable for a grade $3 / 6$ early peaking systolic murmur, best heard at the left upper sternal border and no diastolic murmur, and decreased breath sounds at the bilateral lung bases without crackles. The remainder of his exam was unremarkable and he had no stigmata of endocarditis. The patient had no leukocytosis and laboratory values were largely unremarkable, except for a troponin in the indeterminate range (Table 1) [1-8]. Chest radiograph showed left basilar opacification, consolidation versus pleural effusion, and pulmonary venous congestion (Fig. 2). Shortly after admission, he developed hypoxic respiratory failure and required intubation and admission to the intensive care unit.

Transthoracic echocardiogram showed new prosthetic valvular dysfunction with at least moderate aortic regurgitation and severely elevated transaortic gradients aortic when compared with his last echocardiogram 2 months prior (that showed a normally functioning and a well-seated bioprosthetic valve). He remained afebrile throughout admission, but because of the new valvular dysfunction, there was a suspicion for infective endocarditis and blood cultures were obtained. The patient was started on broad-spectrum antibiotics for suspected aspiration pneumonia. Transesophageal echocardiogram showed an avulsed and perforated bioprosthetic valve cusp resulting in severe aortic regurgitation and severely elevated transaortic gradients (Figs. 3 and 4).

The patient received ceftazidime and metronidazole for suspected aspiration pneumonia. Oxacillin and vancomycin were started when blood cultures began growing gram positive cocci in clusters in four of four bottles. These bacteria were subsequently speciated as $S$. warneri (minimum inhibitory concentration (MIC) to oxacillin $>4 \mu \mathrm{g} /$ $\mathrm{mL}$; MIC to vancomycin $=1 \mu \mathrm{g} / \mathrm{mL}$ ). The patient refused 


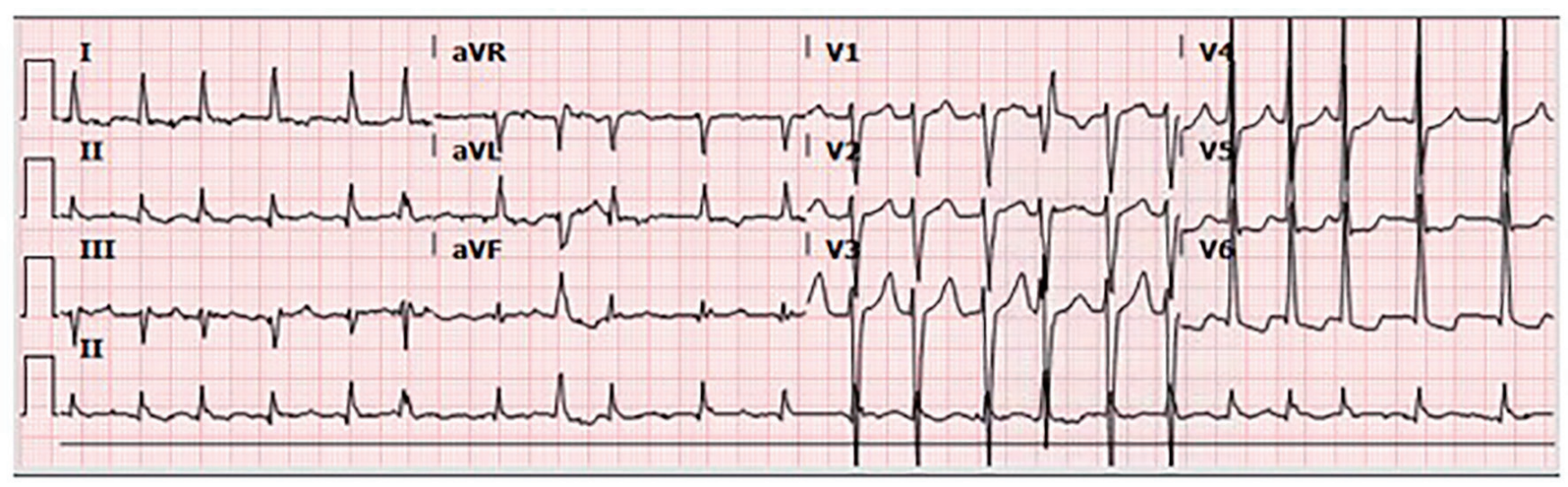

Figure 1. The 12-lead electrocardiogram showing atrial fibrillation with rapid ventricular response and heart rate of 131 beats per minute.

valve replacement surgery and transarterial valve replacement. He had acute kidney injury, thus gentamicin was not given and rifampin $300 \mathrm{mg}$ orally three times daily was added to the vancomycin for the 6-week treatment course. The patient was discharged to a Skilled Nursing Facility to complete his antibiotic course, after which he was lost to

Table 1. Laboratory Values on Hospital Admission

\section{Complete blood count}

White blood cells

Hemoglobin

Hematocrit

Platelets

Coagulation profile

Prothrombin time (PT)

Partial thromboplastin time (PTT)

$14.2 \mathrm{~s}$

International normalized ratio (INR) 1.11

Comprehensive metabolic panel

Sodium

$141 \mathrm{mmol} / \mathrm{L}$

Potassium

Chloride

Bicarbonate

Blood urea nitrogen

Creatinine

Glucose

Albumin

Total protein

Alkaline phosphatase

Alanine amino transferase (ALT)

Aspartate amino transferase (AST)

Total bilirubin

Direct bilirubin

Troponin

$26 \mathrm{mmol} / \mathrm{L}$
$5,500 / \mathrm{mm}^{3}$. Differential: neutrophils $51.9 \%$, lymphocytes $26.7 \%$, monocytes $13.3 \%$, eosinophils $7.1 \%$, basophils $1 \%$.

$11.3 \mathrm{~g} / \mathrm{dL}$

$34.5 \%$

$221,000 / \mathrm{mm}^{3}$
$3.4 \mathrm{mmol} / \mathrm{L}$

$106 \mathrm{mmol} / \mathrm{L}$

$16 \mathrm{mg} / \mathrm{dL}$

$1.06 \mathrm{mg} / \mathrm{dL}$

$101 \mathrm{mg} / \mathrm{dL}$

$3.5 \mathrm{~g} / \mathrm{dL}$

$6.1 \mathrm{~g} / \mathrm{dL}$

$82 \mathrm{U} / \mathrm{L}$

$12 \mathrm{U} / \mathrm{L}$

$18 \mathrm{U} / \mathrm{L}$

$0.7 \mathrm{mg} / \mathrm{dL}$

$0.1 \mathrm{mg} / \mathrm{dL}$

$0.058 \mathrm{mg} / \mathrm{mL}$ (reference ranges: normal $\leq 0.028$; acute myocardial infarction $\geq 0.3$ ) 


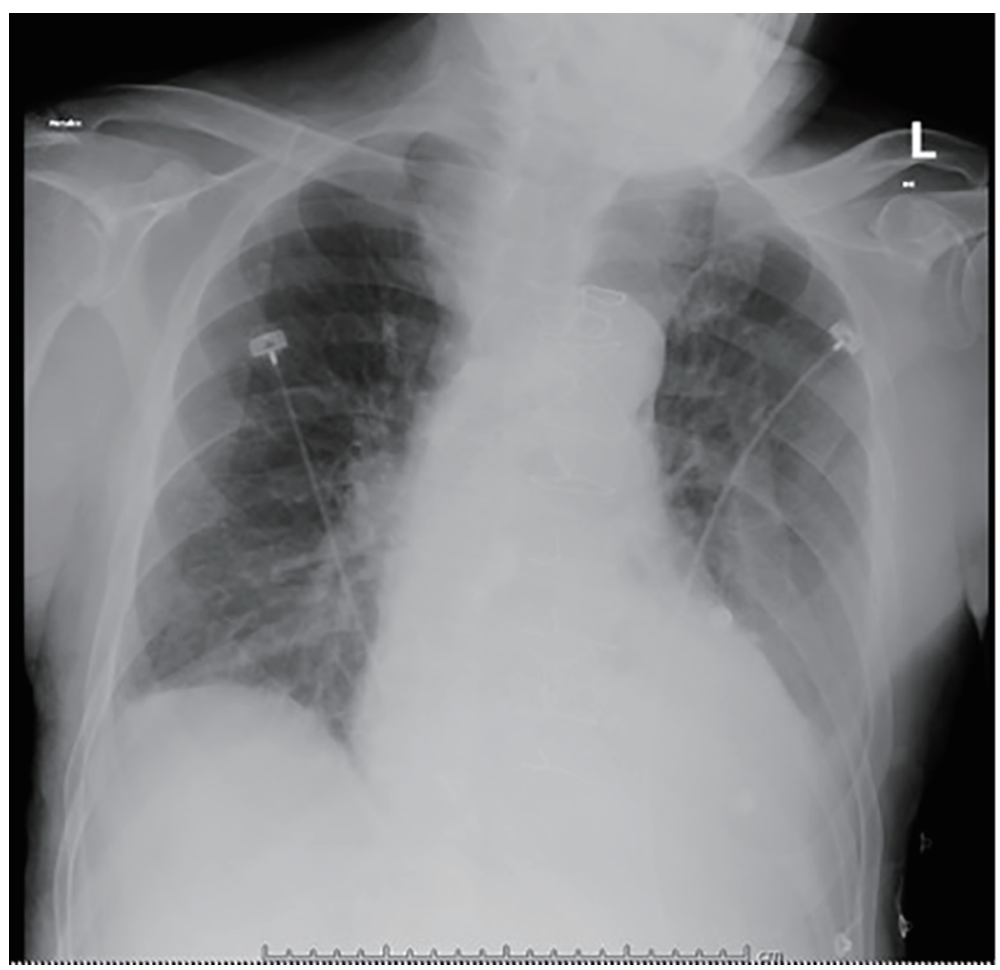

Figure 2. Portable chest X-ray on admission, with opacification of the left lung base (pleural effusion vs. consolidation), scattered density in the right lung base, and pulmonary venous congestion.

follow-up.

\section{Discussion}

There are eight case reports in the English language literature of $S$. warneri causing endocarditis (Table 2). Cases of native valve endocarditis have involved the aortic, mitral, and pulmonic valves and prosthetic valve endocarditis has involved the aortic valve. $S$. warneri is capable of causing aortic ring abscesses and valvular destruction so severe that the patients often require valve replacement surgery [4]. Current recom-

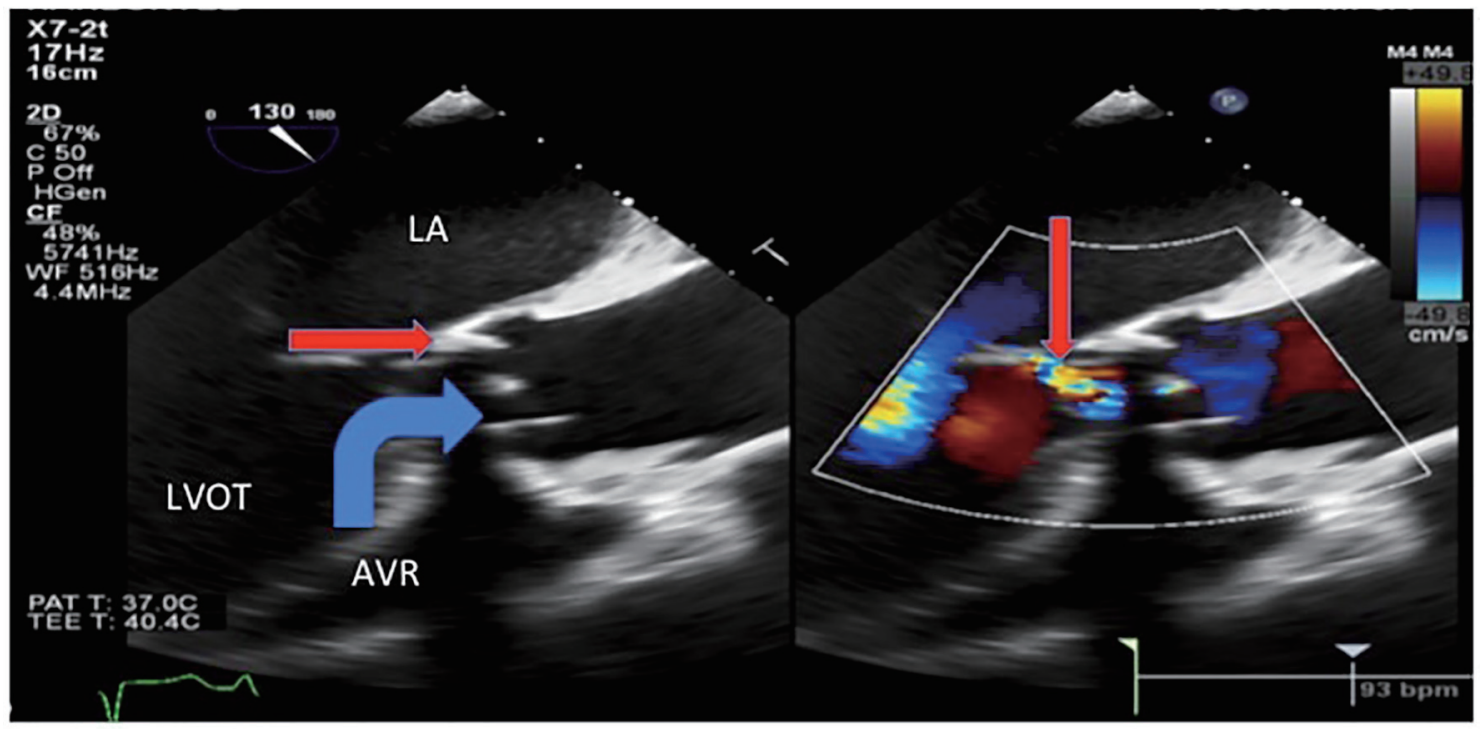

Figure 3. Transesophageal echocardiogram showed severe intravalvular aortic regurgitation (thin arrow) due to an avulsed and prolapsed non-coronary aortic cusp seen here prolapsing into the aortic annulus during systole with the regurgitant jet of intravalvular aortic regurgitation. LA: left atrium. LVOT: left ventricular outflow tract. AVR: aortic valve replacement. 


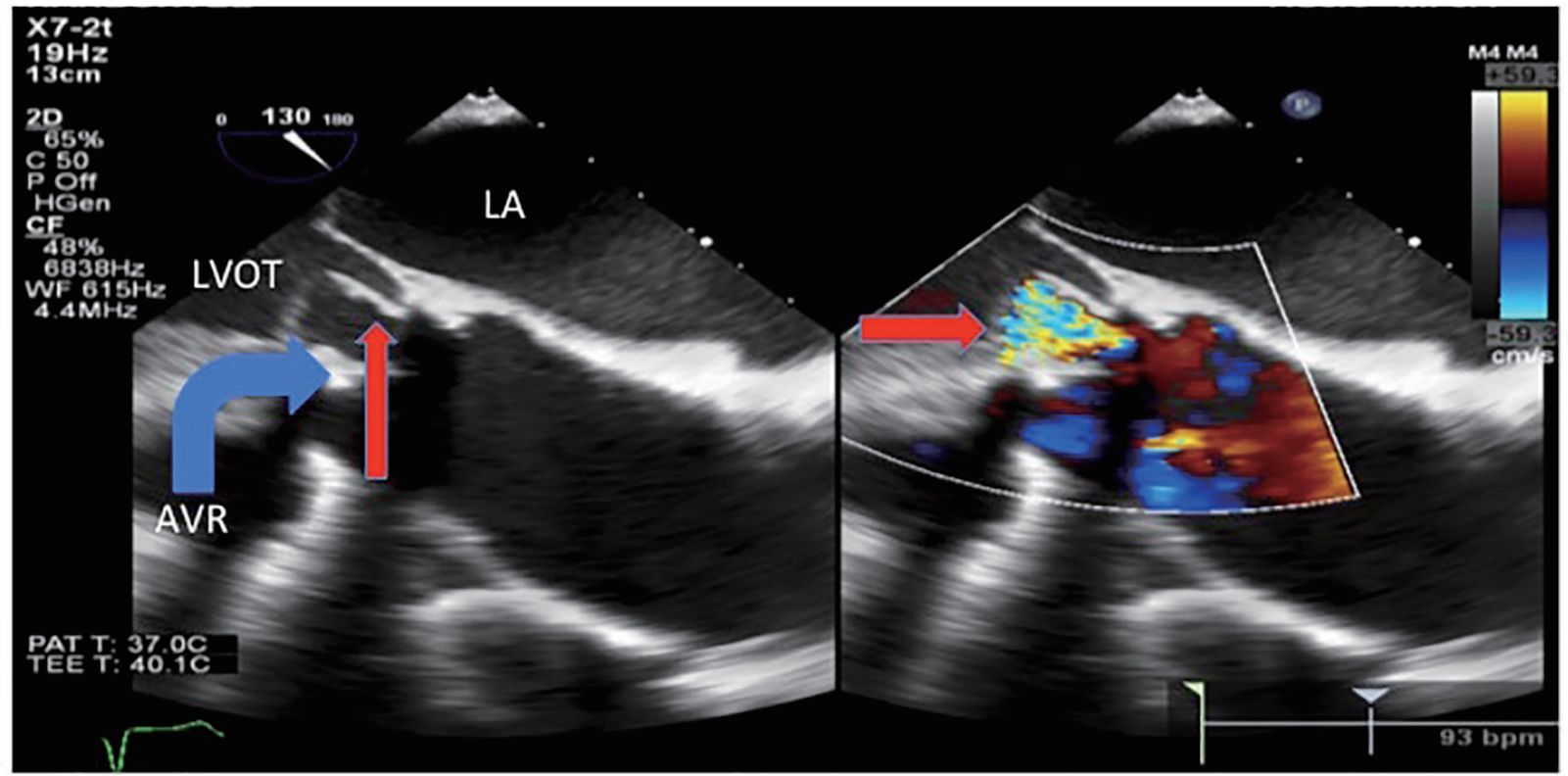

Figure 4. Transesophageal echocardiogram showed an avulsed and prolapsed non-coronary aortic cusp (thin arrow) seen here prolapsing into the LVOT during diastole with the severe intravalvular aortic regurgitation jet. LA: left atrium. LVOT: left ventricular outflow tract. AVR: aortic valve replacement.

Table 2. Review of Previously Published Cases of Staphylococcus warneri Endocarditis

\begin{tabular}{|c|c|c|c|}
\hline Reference & Presenting signs and symptoms & $\begin{array}{l}\text { Valve(s) involved } \\
\text { (native vs. pros- } \\
\text { thetic valve) }\end{array}$ & $\begin{array}{l}\text { Presence of vegetation } \\
\text { and/or intracardiac ab- } \\
\text { scess on echo or surgical } \\
\text { examination }\end{array}$ \\
\hline $\begin{array}{l}\text { Dan et al } \\
(1984)[1]\end{array}$ & $\begin{array}{l}\text { 32-year-old male with fatigue, anorexia, } \mathrm{CP} \text {, fever, tachycardia, } \\
\text { new diastolic murmur and systolic crescendo-decrescendo murmur }\end{array}$ & Aortic (native valve) & Vegetation present \\
\hline $\begin{array}{l}\text { Wood et al } \\
(1989)[2]\end{array}$ & $\begin{array}{l}\text { 66-year-old male with worsening low back pain, became febrile, } \\
\text { XR with vertebral disc prosthesis, disk space narrowing, and end } \\
\text { plate destruction of L } 2-3\end{array}$ & $\begin{array}{l}\text { Aortic and Mitral } \\
\text { (native valves) }\end{array}$ & $\begin{array}{l}\text { Vegetations on both } \\
\text { valves and aortic } \\
\text { valve ring abscess }\end{array}$ \\
\hline $\begin{array}{l}\text { Kamath et al } \\
(1992)[3]\end{array}$ & $\begin{array}{l}\text { 64-year-old male with fevers, subconjunctival hemorrhage, } \\
\text { slinter hemorrhages, systolic murmur, and diastolic murmur }\end{array}$ & $\begin{array}{l}\text { Mitral, aortic, and } \\
\text { pulmonary valves }\end{array}$ & Vegetations on all 3 valves \\
\hline $\begin{array}{l}\text { Abgrall et al } \\
(2001)[8]\end{array}$ & $\begin{array}{l}71 \text {-year-old male s/p aortic valve replacement } 5 \text { days } \\
\text { prior, afebrile, no leukocytosis. Blood cultures negative; } \\
\text { culture of vegetation tags with } S \text {. warneri }\end{array}$ & Aortic (prosthetic valve) & $\begin{array}{l}\text { Vegetation present } \\
\text { with suspected aortic } \\
\text { valve ring abscess }\end{array}$ \\
\hline $\begin{array}{l}\text { Kini et al } \\
(2010)[5]\end{array}$ & $\begin{array}{l}\text { 78-year-old female with cough, pleural effusions, and bilateral } \\
\text { lower extremity edema with clear serous discharge }\end{array}$ & Mitral (native valve) & Vegetation present \\
\hline $\begin{array}{l}\text { Arslan et al } \\
(2011)[6]\end{array}$ & $\begin{array}{l}\text { 43-year-old female with aortic valve replacement } 3 \text { years prior } \\
\text { with recent prosthetic valve endocarditis due to } S \text {. warneri } 3 \\
\text { months prior, presented with } 20 \text { days of fevers, night sweats }\end{array}$ & $\begin{array}{l}\text { Aortic valve } \\
\text { (prosthetic valve) }\end{array}$ & Vegetation present \\
\hline $\begin{array}{l}\text { Bhardwaj et } \\
\text { al (2016) [7] }\end{array}$ & $\begin{array}{l}59 \text {-year-old male with history of scalp laceration } 2 \text { weeks } \\
\text { prior presenting with } 3 \text { days of lethargy, abdominal pain, } \\
\text { acute kidney injury, and hypotensive, pansystolic murmur }\end{array}$ & Mitral (native valve) & $\begin{array}{l}\text { Vegetations present } \\
\text { (two in total) }\end{array}$ \\
\hline $\begin{array}{l}\text { Current case } \\
(2017)\end{array}$ & $\begin{array}{l}67 \text {-year-old male with valve replacement } 7 \text { months prior, presenting } \\
\text { with chest pain, constitutional symptoms, no documented fever }\end{array}$ & Aortic (prosthetic valve) & $\begin{array}{l}\text { No vegetations or Aortic } \\
\text { valve ring abscess }\end{array}$ \\
\hline
\end{tabular}


mendations for methicillin-resistant coagulase negative staphylococcal prosthetic valve endocarditis are a combination of vancomycin and rifampin for 6 weeks, and gentamicin for the first 2 weeks [9].

This case is unique because it highlights that endocarditis caused by relatively low virulence pathogens can present with symptoms that are predominantly non-infectious. CoNS tend to be less virulent bacteria and often require the presence prosthetic material to cause disease [2]. They are adept at forming biofilms and they have fewer numbers and "less aggressive" virulence factors compared to Staphylococcus aureus [10].

While the lack of fever and other signs and symptoms of infection may be due to the low virulence pathogen, host factors may have also been involved in this patient's atypical presentation. Elderly patients may have "blunted or absent" febrile responses to severe infections in approximately 20$30 \%$ of cases [11]. Perhaps a combination of a relatively lower organism virulence, older age, and the absence of vegetations (suggesting a milder case of endocarditis) explains why this patient lacked fever and leukocytosis.

In summary, clinicians should consider endocarditis caused by relatively low virulence organisms such as $S$. warneri in patients with a prosthetic valve presenting with new $\mathrm{CHF}$ or valvular dysfunction even if the patient lacks typical signs of infections such as fever and leukocytosis, especially if the patient is of advanced age.

\section{References}

1. Dan M, Marien GJ, Goldsand G. Endocarditis caused by Staphylococcus warneri on a normal aortic valve following vasectomy. Can Med Assoc J. 1984;131(3):211-213.

2. Wood CA, Sewell DL, Strausbaugh LJ. Vertebral osteomyelitis and native valve endocarditis caused by
Staphylococcus warneri. Diagn Microbiol Infect Dis. 1989;12(3):261-263.

3. Kamath U, Singer C, Isenberg HD. Clinical significance of Staphylococcus warneri bacteremia. J Clin Microbiol. 1992;30(2):261-264.

4. Stollberger C, Wechsler-Fordos A, Geppert F, Gulz W, Brownstone E, Nicolakis M, Finsterer J. Staphylococcus warneri endocarditis after implantation of a lumbar disc prosthesis in an immunocompetent patient. J Infect. 2006;52(1):e15-18.

5. Kini GD, Patel K, Parris AR, Tang JS. An unusual presentation of endocarditis caused by Staphylococcus warneri. Open Microbiol J. 2010;4:103-105.

6. Arslan F, Saltoglu N, Mete B, Mert A. Recurrent Staphylococcus warnerii prosthetic valve endocarditis: a case report and review. Ann Clin Microbiol Antimicrob. 2011;10:14.

7. Bhardwaj B, Bhatnagar UB, Conaway DG. An Unusual Presentation of Native Valve Endocarditis Caused by Staphylococcus warneri. Rev Cardiovasc Med. 2016;17(3-4):140-143.

8. Abgrall S, Meimoun P, Buu-Hoi A, Couetil JP, Gutmann L, Mainardi JL. Early prosthetic valve endocarditis due to Staphylococcus warneri with negative blood culture. J Infect. 2001;42(2):166.

9. Baddour LM, Wilson WR, Bayer AS, Fowler VG, Jr., Tleyjeh IM, Rybak MJ, Barsic B, et al. Infective endocarditis in adults: diagnosis, antimicrobial therapy, and management of complications: a scientific statement for healthcare professionals from the American heart association. Circulation. 2015;132(15):1435-1486.

10. Becker K, Heilmann C, Peters G. Coagulase-negative staphylococci. Clin Microbiol Rev. 2014;27(4):870-926.

11. Norman DC. Fever in the elderly. Clin Infect Dis. 2000;31(1):148-151. 